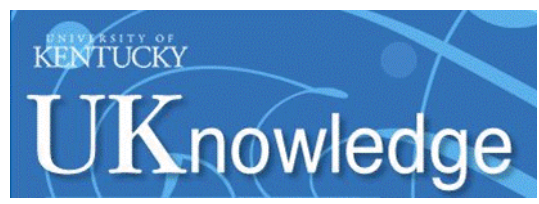

University of Kentucky

UKnowledge

$11-10-2015$

\title{
Reliability of Isometric and Eccentric Isokinetic Shoulder External Rotation
}

\author{
Brianna M. Papotto \\ University of Kentucky, brianna.papotto@uky.edu \\ Thomas Rice \\ University of Kentucky \\ Terry Malone \\ University of Kentucky, trmalo1@pop.uky.edu \\ Timothy Butterfield \\ University of Kentucky, tim.butterfield@uky.edu \\ Tim L. Uhl \\ University of Kentucky, tluhl2@uky.edu
}

Follow this and additional works at: https://uknowledge.uky.edu/rehabsci_facpub

Part of the Rehabilitation and Therapy Commons

Right click to open a feedback form in a new tab to let us know how this document benefits you.

\section{Repository Citation}

Papotto, Brianna M.; Rice, Thomas; Malone, Terry; Butterfield, Timothy; and Uhl, Tim L., "Reliability of Isometric and Eccentric Isokinetic Shoulder External Rotation" (2015). Physical Therapy Faculty Publications. 58.

https://uknowledge.uky.edu/rehabsci_facpub/58

This Article is brought to you for free and open access by the Physical Therapy at UKnowledge. It has been accepted for inclusion in Physical Therapy Faculty Publications by an authorized administrator of UKnowledge. For more information, please contact UKnowledge@lsv.uky.edu. 
Reliability of Isometric and Eccentric Isokinetic Shoulder External Rotation

Notes/Citation Information

To be published in Journal of Sport Rehabilitation.

๑ 2015 Human Kinetics, Inc. as accepted for publication. http://dx.doi.org/10.1123/jsr.2015-0046

This article is available at UKnowledge: https://uknowledge.uky.edu/rehabsci_facpub/58 


\section{Note: This article will be published in a forthcoming issue of the Journal of Sport Rehabilitation. The article appears here in its accepted, peer-reviewed form, as it was provided by the submitting author. It has not been copyedited, proofed, or formatted by the publisher.}

Section: Technical Report

Article Title: Reliability of Isometric and Eccentric Isokinetic Shoulder External Rotation

Authors: Brianna M Papotto*, Thomas Rice*, Terry Malone†, Timothy Butterfield*, and Tim L. Uhl*

Affiliations: *Department of Rehabilitation Science, Athletic Training, University of Kentucky, Lexington, KY. Department of Rehabilitation Science, Physical Therapy, University of Kentucky, Lexington, KY.

Journal: Journal of Sport Rehabilitation

Acceptance Date: October 22, 2015

(C)2015 Human Kinetics, Inc.

DOI: $\underline{\text { http://dx.doi.org/10.1123/jsr.2015-0046 }}$ 
Reliability of Isometric and Eccentric Isokinetic Shoulder External Rotation

Brianna M Papotto, ATC*

Thomas Rice, MS, ATC*

Terry Malone, PT EdD, ATC, FAPTA†

Timothy Butterfield, PhD, ATC*

Tim L. Uhl, PhD, PT, ATC, FNATA*

*Department of Rehabilitation Science, Athletic Training, University of Kentucky, Lexington, $\mathrm{KY}$

†Department of Rehabilitation Science, Physical Therapy, University of Kentucky, Lexington, $\mathrm{KY}$

This study was approved by the University of Kentucky Institutional Review Board.

Corresponding Author:

Tim Uhl

900 S. Limestone

Lexington, KY 40536-0200

tluhl2@uky.edu 
"Reliability of Isometric and Eccentric Isokinetic Shoulder External Rotation" by Papotto BM et al.

Journal of Sport Rehabilitation

(C) 2015 Human Kinetics, Inc.

\section{Abstract:}

Context: Shoulder external rotators are challenged eccentrically throughout the deceleration phase of throwing which is thought to contribute to overuse injuries. In order to evaluate the effectiveness of intervention programs as well as identify deficits, reliable and responsive measures of isometric and eccentric shoulder external rotation are necessary. Previously, isometric measures have primarily tested a single position and eccentric measures have not been found to have high reliability. Objective: To examine the between day reliability of multiple angle isometric and dynamic eccentric isokinetic testing of shoulder external rotation. Design: Repeated measures Participants: 10 healthy subjects (age: $30 \pm 12$ years, height: $166 \pm 13 \mathrm{~cm}$, mass: $72 \pm 10 \mathrm{~kg}$ ) Main

Outcome Measures: Average isometric peak torque of shoulder external rotation at 7 angles was measured. From these values, the angle of isometric peak torque was calculated. Dynamic eccentric average peak torque, average total work and average angle of peak torque were measured. Results: Between day reliability was high for average peak torque during isometric contractions at all angles (ICC $\geq 0.85$ ) as well as dynamic eccentric average peak torque (ICC $\geq 0.97)$ between days. The estimated angle of isometric peak torque (ICC $\leq 0.65$ ) was not highly reliable between days. The average angle of peak torque from the eccentric testing produced inconsistent results. Average total work of dynamic eccentric shoulder external rotation was found to be highly reliable between days (ICC $\geq 0.97$ ). Conclusion: Measures of force such as peak torque and total work, in isometric and eccentric testing of the shoulder external rotator muscles can be measured reliably between days and used to objectively evaluate shoulder strength and identify changes when they occur. Angle measurements of peak torque could provide insight into the mechanical properties of the posterior shoulder muscles but were found to be inconsistent between days. 
"Reliability of Isometric and Eccentric Isokinetic Shoulder External Rotation" by Papotto BM et al.

Journal of Sport Rehabilitation

(C) 2015 Human Kinetics, Inc.

\section{Introduction}

Shoulder pathology is one of the most common ailments in both the athletic and general population ${ }^{1,2}$. Whether due to work or sport related activity, there are often imbalances in the shoulder musculature that can lead to maladaptive changes that can become the primary source of pain ${ }^{3-5}$. The shoulder external rotators are challenged eccentrically throughout the deceleration phase of throwing which is thought to contribute to overuse injuries ${ }^{6}$. In a similar manner, repetitive selective training of the internal rotators, such as what occurs during the swimming motion, has also been shown to result in muscular imbalances in the shoulder and subsequently chronic shoulder pain ${ }^{3}$. In order to evaluate the effectiveness of intervention programs as well as identify deficits, reliable and responsive measures of isometric and eccentric shoulder external rotation are necessary. Previously, isometric measures have been found to be reliable but have primarily been tested in a single position that does not provide strength assessment throughout the arc of motion. Concentric measures have also been found to be reliable for assessing shoulder internal and external rotation ${ }^{7,8}$. Eccentric measures, however, have not been found to be consistently reliable ${ }^{9-11}$. This could be attributed to the complexity and novelty of eccentric movements for many subjects during testing.

The purpose of this study was to examine the between day reliability of seven isometric angles in order to estimate angle of peak torque. Further, to examine reliability between days for dynamic eccentric isokinetic testing of shoulder external rotation. By establishing reliable measures these procedures can be used to evaluate effectiveness of intervention programs addressing shoulder external rotation. Determining the reliability 
for dynamic eccentric isokinetic testing is especially important to this study as this method has been determined to be inconsistent in previous studies.

\section{Methods}

Ten participants volunteered for this study from a sample of convenience at a university setting. (Age: $30 \pm 12$ years, Height: $166 \pm 13 \mathrm{~cm}$, Mass: $72 \pm 10 \mathrm{~kg}$ ). Subjects were excluded from participation if they reported a history of shoulder or neck pathology, previous shoulder or neck surgery, or shoulder or neck pain within the last 6 months. Eligible subjects completed a Penn Shoulder Scale before testing to evaluate level of shoulder function prior to participation in the study. The mean Penn Shoulder Score was 99 with a range (94-100) indicating participants demonstrated normal function at the onset of the study. All subjects read and signed a University of Kentucky Institutional Review Board approved informed consent prior to participation in the study.

This study was designed to establish that shoulder external rotation isometric measures of average peak torque and an estimate of the isometric angle of peak torque, using a second order polynomial, could be measured reliably between days. Additionally, dynamic eccentric average peak torque (DEAPT), average total angular impulse, and angle of peak torque were measured to determine the reliability of eccentric shoulder external rotation measures across 3 weeks of testing. In total, 11 different measures were used to establish the reliability of our testing procedures. Previous research ${ }^{9,12}$ has examined isometric peak torque in one or two positions but this study utilized 7 different positions of isometric external rotation in addition to analyzing the estimated angle of isometric peak torque, DEAPT, average total angular impulse and dynamic eccentric angle of peak torque. The independent variable was time. The dependent measures are 
"Reliability of Isometric and Eccentric Isokinetic Shoulder External Rotation" by Papotto BM et al.

Journal of Sport Rehabilitation

(C) 2015 Human Kinetics, Inc.

isometric external rotation average peak torque at 7 angles $\left(\mathrm{ER} 45^{\circ}, 30^{\circ}, 15^{\circ}, 0^{\circ}, \mathrm{IR} 15^{\circ}\right.$, $30^{\circ}, 45^{\circ}$, estimated angle of isometric peak torque, DEAPT, average total angular impulse, and average angle of peak torque.

Prior to each day of shoulder external rotation testing all participants completed a warm-up of 3 shoulder stretches for the posterior and anterior shoulder musculature with each stretch repeated twice for 30 seconds. Participants then warmed up with two active arm motions of side-lying external/internal rotation and side-lying horizontal abduction/adduction without resistance for 1 minute each.

All shoulder strength testing was performed using an isokinetic dynamometer (Cybex Norm, Ronkonkoma, NY). Participants were positioned in the scapular plane neutral position while seated with their dominant shoulder in $60^{\circ}$ of abduction and $30^{\circ}$ of horizontal adduction. (See Figures 1-2) This testing position is a slight modification from the methods of previous studies ${ }^{9,12}$. The positions were confirmed with a universal goniometer. Isometric testing was performed first and angle of testing was randomly assigned using a random number generator within Microsoft Excel on each testing day to minimize fatigue bias.

Isometric testing was completed in 7 different positions. In each position, subjects performed one sub-maximal practice repetition for 3 seconds, rested for 20 seconds and then performed two maximal repetitions for 3 -seconds with a 60 second rest between each trial ${ }^{13}$. Standardized verbal encouragement was given during isometric strength testing to attempt to maximize the subject's effort and strength potential ${ }^{14}$. Peak torque values of the two contractions were averaged to represent an individual's effort at each 
angle. The average torque at each angle was used for statistical analysis to determine isometric reliability.

In addition to calculating the average torque, isometric data at each angle was scatter plotted in Microsoft Excel for each trial. A second order polynomial regression line was plotted and the angle of peak torque was estimated from this curve for both trials. This method has been previously described by Butterfield et $\mathrm{al}^{15}$ to determine angle of peak torque from isometric contractions in an animal model.

Dynamic eccentric shoulder external rotation data were collected in the same arm position and through $55^{\circ}$ of external rotation to $55^{\circ}$ of internal rotation. The continuous passive motion (CPM) mode was used for testing. The internal rotation velocity was set

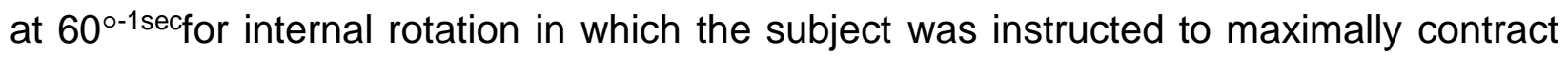
into external rotation just prior to initiation of internal rotation. The subject was instructed to maximally resist internal rotation through the entire range of motion to evaluate eccentric external rotation strength. The subject was instructed to relax their arm as it was passively returned into external rotation by the device at $15^{\circ-1 \mathrm{sec}}$ to eliminate all concentric activity. Subjects were allowed 3 practice trials to familiarize themselves with this novel movement. After 3 minutes of rest, subjects performed 6 maximal efforts in a row with 7 seconds of recovery during the passive return to full external rotation between trials. The middle 4 of the 6 trials were averaged and used in statistical analysis for DEAPT, average total angular impulse and average angle of peak torque. Standardized verbal encouragement was given for all eccentric testing ${ }^{14}$.

Subjects returned to the lab to collect the same data at 1 week from the initial testing and again 2 weeks from the initial testing for a total of 3 tests. Three sessions 
"Reliability of Isometric and Eccentric Isokinetic Shoulder External Rotation" by Papotto BM et al.

Journal of Sport Rehabilitation

(C) 2015 Human Kinetics, Inc.

were performed to investigate the potential effect of motor learning that can occur while undergoing strength testing particularly for a novel task such as maximal eccentric contractions. These data for the 3 sessions were used to establish reliability testing between days 1-2 and 2-3. Independent intraclass correlation coefficients were used to examine between day reliability for all dependent measures. Two-way random model consistent with an ICC $(2, \mathrm{k})$ was performed using SPSS version 22 (IBM, Armonk, NY) ${ }^{16}$

\section{Results}

Descriptive data for all 11 dependent measures is presented with means and standard deviations in Table 1. Isometric shoulder external rotation average peak torque proved to be a very reliable measure for all tested angles between days 1-2 and 2-3 (ICC $\geq 0.85$ ). (See Table 2) The estimated angle of isometric peak torque calculated from the isometric contractions at 7 angles was not reliable between days $1-2($ ICC $=-0.003)$ but had fair reliability between days 2-3 $(I C C=0.65)$. Dynamic eccentric average total angular impulse and average peak torque were reliable between days 1-2 and 2-3 (See Table 2). The average angle of peak torque measured from dynamic shoulder eccentric external rotation had excellent reliability between days $1-2(I C C=0.93)$ but was fair between days 2-3 $($ ICC $=0.51)$.

\section{Discussion}

The results of this study demonstrated that measures of force in isometric shoulder external rotation average peak torque, dynamic eccentric average peak torque and dynamic eccentric average total angular impulse can be measured reliably between days. However, the angle of peak torque predicted from 7 angles of isometric contractions and average angle of peak torque during dynamic eccentric testing were found to have greater 
"Reliability of Isometric and Eccentric Isokinetic Shoulder External Rotation" by Papotto BM et al.

Journal of Sport Rehabilitation

(C) 2015 Human Kinetics, Inc.

variability and were not consistent measures. The ability to consistently produce force in external rotation is very good in shoulder external rotation however the findings of this study suggest that in the general population of healthy shoulders the angle at which peak torque can be produced is not well controlled in external rotation. Mean and peak torque values are better and more reliable for measuring strength changes as opposed to using angle measurements.

To the best of our knowledge, this is the first study to assess isometric shoulder external rotation strength at multiple angles throughout the middle arc of shoulder range of motion. Previous studies have determined that isometric shoulder external rotation can be measured reliably at a single angle or a few positions. Malerba et al. reported ICC values $\geq 0.81$ for isometric external rotation at $20^{\circ}$ and $60^{\circ}$ of shoulder external rotation using an isokinetic dynamometer with the arm positioned in $45^{\circ}$ of abduction, $30^{\circ}$ of horizontal adduction, and $90^{\circ}$ of elbow flexion which is similar to our current study ${ }^{9}$. Similarly, MacDermid et al. reported an ICC $=0.90$ in their study when evaluating external rotation using an isokinetic dynamometer at $0^{\circ}$ of shoulder ER and the same arm positioning as was used in Malerba's study ${ }^{12}$. We tested 7 different angles in order to estimate the isometric angle of peak torque ${ }^{15}$. This provides a more comprehensive assessment of shoulder strength throughout the range of motion as well as a more accurate portrayal of the mechanical properties of the muscles being tested. For this reason, it was important to establish that isometric peak torque could be measured reliably at each angle to accurately assess strength changes throughout the range of motion. 
The results of this study demonstrated good test-retest reliability for isometric shoulder external rotation peak torque at all 7 angles. The reliability of our study was consistently high with low measurement error ranging from $0.9-2.5 \mathrm{Nm}$ at all angles between days and generated values similar to previous studies, therefore we are confident that with values of approximately $1.3-3.5 \mathrm{Nm}$ representing minimal detectable change (MDC) that this testing procedure would be able to detect a change in strength when one occurs. Measuring at multiple angles will help provide a more complete representation of muscle function throughout the arc of motion and may allow us to identify deficits in an injured population in the future.

The average total impulse and average peak torque for dynamic eccentric shoulder external rotation were found to be reliable. While the results of previous studies are inconsistent, our study revealed these measures of eccentric shoulder external rotation can be measured reliably. Edouard et al., ${ }^{11}$ demonstrated comparable ICC results to the current study, ranging from $0.87-0.97$. Utilizing similar testing methods however eccentric testing was performed at a slower speed of $30^{\circ-1}-1 \mathrm{sec}$ across 70 degrees of motion and performed resistance in two directions. The slower speed of movement may have improved consistency of torque output as the subjects had over 2 seconds of eccentric resistance in both directions. Contrary to these results, Malerba et al. ${ }^{9}$ reported ICC values for the between day reliability of eccentric average work and peak torque to be equal to 0.58 and 0.44 respectively using a similar testing method as Edouard but at a speed of $60^{\circ-1 \mathrm{sec}}$ which is similar to the current study. However, Malerba et al., tested subjects across painfree arcs of motion, not defined by the investigators which could affected their reliability and torque outputs. These authors further speculated their low 
ICC values to the complexity of the eccentric testing and the subjects' unfamiliarity with the movement. We agree with this statement and in our study limited cognitive demand by only testing eccentric external rotation. No other dynamic motions were tested which may account for our higher reliability values for eccentric testing.

In the literature, total work and total impulse are used synonymously to define the area under the curve. In Malerba's study, total work was defined as the area under the torque curves where work was equal to the magnitude of the force times the distance, where the distance was the angular displacement of the limb. For our study, this same measurement was termed total angular impulse to better represent the area under the curve as the product of the torque applied by the subject multiplied by its time of application $\left.(1 / 2 \text { [torque at point } A+\text { torque at point } B]^{*} .01\right)^{17}$. These measurements of work and angular impulse are comparable and vary only based on the units used for the calculation. For the purpose of this study, time was used whereas Malerba used a unit of distance to report the changes in torque. Malerba reported the measurement error was equal to $26.3 \mathrm{Nm}^{*}$ s with a minimal detectable change of $37.2 \mathrm{Nm}^{*} \mathrm{~s}$. While the SEM for average peak torque was equal to $10.8 \mathrm{Nm}$ and $\mathrm{MDC}, 15.3 \mathrm{Nm}$.

In addition to the high reliability values for dynamic eccentric average total angular impulse and average peak torque, the results of our study also had relatively low measurement error (SEM $\leq 2.0 \mathrm{Nm}^{*} \mathrm{~s}$ ) and minimal detectable change (MDC $\leq 2.8 \mathrm{Nm}^{*} \mathrm{~s}$ ). The combination of these three variables contribute to the ability for these testing methods to be used as a tool for evaluating subtle changes in shoulder external rotation strength, particularly in the ability to see changes at any point throughout the range of motion. Analyzing the average total angular impulse offers a more complete representation of the 
"Reliability of Isometric and Eccentric Isokinetic Shoulder External Rotation" by Papotto BM et al.

Journal of Sport Rehabilitation

(C) 2015 Human Kinetics, Inc.

amount of effort throughout the entire arc of motion tested as opposed to the peak torque that represents only a single point in the arc of motion during a dynamic eccentric testing. By examining the total arc of motion, deficits and improvement can be readily identified during testing and rehabilitation process.

As mentioned previously, studies have demonstrated that shoulder internal and external rotation strength measurements are reliable when tested concentrically. Mandalidis et $\mathrm{al}^{10}$ tested subjects using a Kincom II dynamometer in a similar testing position to the one used in our current study. Across $60^{\circ}$ of shoulder rotation, concentric measures for all subjects' mean peak and average moment produced ICC values greater than 0.80 whereas ICC values for the eccentric measures were greater than 0.76 . Our study revealed ICC values ranging from $0.97-0.98$ for dynamic eccentric peak torque and average angular impulse. Although it is difficult to make direct comparisons between the two studies as different outcome measures were used for each, it is important to recognize the improved reliability of eccentric measures in the current study.

The average between day reliability for angle of peak torque during dynamic eccentric shoulder external rotation was fair. When analyzing the results of Day 1 to Day 2, a high reliability value is reported (ICC=0.93). However, from Day 2 to Day 3 , the reliability is considerably lower $(I C C=0.51)$ resulting in an average $I C C=0.72$. This variability can be accounted for through analysis and recognition of outliers in the data. When the single outlier is removed, the average ICC value improves to 0.88 . In addition to the removal of the outlier, it is important to note the great amount of variability present in the angle measurements during isokinetic testing. Our study reported SEM values ranging from $6.5-14.8^{\circ}$ for this measurement. The use of human subjects also greatly 
"Reliability of Isometric and Eccentric Isokinetic Shoulder External Rotation" by Papotto BM et al.

Journal of Sport Rehabilitation

(C) 2015 Human Kinetics, Inc.

increases the chances that external factors may contribute to the variability such as what was observed in our study. Motivation and incentive can alter a subject's performance on maximal effort tests. We attempted to control for these factors by using standardized verbal encouragement, which has been shown to improve performance. ${ }^{14}$ Despite our best efforts, it is possible that variations in these factors could influence each subject's performance during testing and consequently where the angle of peak torque occurs dynamically.

Using the average torque values from the 7 angles of isometric testing, we were able to calculate the predicted angle at which the shoulder external rotators would generate the greatest force. This value, however, produced a poor reliability measure. It is interesting to note the mechanical properties of the posterior shoulder musculature that are demonstrated in the results of our study. Previous studies have found that muscles are less capable of generating maximal forces at longer lengths. This has been well established in the quadriceps muscle. In one study, Babault et al. found that the knee extensor torque produced by human subjects during isometric maximal voluntary contraction was significantly lower when the leg was close to full extension ${ }^{18}$. However, in this study, we found that even at greater lengths the posterior shoulder muscles working synergistically were able to maintain or continue generating an equal amount of force (Figure 3). While the reliability of the predicted angle was poor, we believe this finding to still be of great importance in assessing the mechanical properties of the posterior shoulder muscles.

There are several limitations to this study. Our sample population consisted solely of healthy subjects and testing was conducted on the dominant extremity only. Training 
status of each subject was also not identified as a determining factor for inclusion in the study. It is unknown whether we would obtain similar results if the subject's level of training prior to the study was assessed. We measured shoulder external rotation not a particular individual muscle such as infraspinatus or trapezius. Therefore we cannot attribute performance to a specific muscle as the scapulohumeral and axioscapular muscles work synergistically to perform shoulder external rotation. The small sample size of this study also raises some concerns in the confidence of our results. Despite the small sample size, especially in comparison to similar studies, further analysis of our data determined there was no change in the ICC values when a single subject was removed. In order to establish greater reliability, research is needed with an increased sample size.

In this study we have shown that isometric and dynamic eccentric average total angular impulse and average peak torque can be measured reliably for shoulder external rotation. Each of these measures were found to demonstrate low measurement error indicating these measurement methods could effectively detect strength changes from training or identify deficits when the occur. Fair reliability was demonstrated for the average angle of peak torque during eccentric external rotation. While the estimated angle of isometric peak torque demonstrated poor reliability, this measure has been used by previous researcher ${ }^{19}$ to show the effects of eccentric training and could provide further insight into the mechanical properties of the posterior shoulder muscles but caution should be exercised in using this measure to evaluate change overtime due to inconsistency of the measure in shoulder external rotation. 
"Reliability of Isometric and Eccentric Isokinetic Shoulder External Rotation" by Papotto BM et al. Journal of Sport Rehabilitation

(C) 2015 Human Kinetics, Inc.

\section{Acknowledgements}

The project described was supported by the National Center for Advancing Translational

Sciences, National Institutes of Health, through grant number UL1TR000117. The content is solely the responsibility of the authors and does not necessarily represent the official views of the $\mathrm{NIH}$. 
"Reliability of Isometric and Eccentric Isokinetic Shoulder External Rotation" by Papotto BM et al.

Journal of Sport Rehabilitation

(C) 2015 Human Kinetics, Inc.

\section{References}

1. Luime J.J. ea. Prevalence and incidence of shoulder pain in the general population; a systematic review. Scand J Rheumatol. 2004;33(2):73-81.

2. McFarland EG, Wasik M. Epidemiology of collegiate baseball injuries. Clinical journal of sport medicine : official journal of the Canadian Academy of Sport Medicine. 1998;8(1):10-13.

3. Rupp S, Berninger K, Hopf T. Shoulder problems in high level swimmers-impingement, anterior instability, muscular imbalance? International journal of sports medicine. 1995;16(8):557-562.

4. Ludewig PM, Borstad JD. Effects of a home exercise programme on shoulder pain and functional status in construction workers. Occupational and environmental medicine. 2003;60(11):841-849.

5. Frost $\mathrm{P}$, Bonde JP, Mikkelsen $\mathrm{S}$, et al. Risk of shoulder tendinitis in relation to shoulder loads in monotonous repetitive work. American journal of industrial medicine. 2002;41(1):11-18.

6. Fleisig GS, Andrews JR, Dillman CJ, Escamilla RF. Kinetics of baseball pitching with implications about injury mechanisms. The American journal of sports medicine. 1995;23(2):233-239.

7. Hill A, Pramanik S, McGregor A. Isokinetic dynamometry in assessment of external and internal axial rotation strength of the shoulder: Comparison of two positions. Isokinetics and exercise science. 2005;13(3):187-195.

8. Anderson VB, Bialocerkowski AE, Bennell KL. Test-retest reliability of glenohumeral internal and external rotation strength in chronic rotator cuff pathology. Physical Therapy in Sport. 2006;7(3):115-121.

9. Malerba JL, Adam ML, Harris BA, Krebs DE. Reliability of dynamic and isometric testing of shoulder external and internal rotators. The Journal of orthopaedic and sports physical therapy. 1993;18(4):543-552.

10. Mandalidis DG, Donne B, O'Regan M, O'Brien M. Reliability of isokinetic internal and external rotation of the shoulder in the scapular plane. Isokinetics and Exercise Science 2001;9:65-72.

11. Edouard P, Codine P, Samozino P, Bernard PL, Herisson C, Gremeaux V. Reliability of shoulder rotators isokinetic strength imbalance measured using the Biodex dynamometer. Journal of science and medicine in sport / Sports Medicine Australia. 2013;16(2):162-165.

12. MacDermid JC, Ramos J, Drosdowech D, Faber K, Patterson S. The impact of rotator cuff pathology on isometric and isokinetic strength, function, and quality of 
life. Journal of shoulder and elbow surgery / American Shoulder and Elbow Surgeons ... [et al.]. 2004;13(6):593-598.

13. Philippou A, Bogdanis GC, Nevill AM, Maridaki M. Changes in the angle-force curve of human elbow flexors following eccentric and isometric exercise. European journal of applied physiology. 2004;93(1-2):237-244.

14. McNair PJ, Depledge J, Brettkelly M, Stanley SN. Verbal encouragement: effects on maximum effort voluntary muscle action. British journal of sports medicine. 1996;30(3):243-245.

15. Butterfield TA, Herzog W. Is the force-length relationship a useful indicator of contractile element damage following eccentric exercise? Journal of biomechanics. 2005;38(9):1932-1937.

16. Shrout PE, Fleiss JL. Intraclass correlations: uses in assessing rater reliability. Psychological bulletin. 1979;86(2):420-428.

17. Kreighbaum EB, KM. Biomechanics: a qualitative approach for studying human movement. 4th ed. Needham Heights, MA: Allyn \& Bacon; 1996.

18. Babault N, Pousson M, Michaut A, Van Hoecke J. Effect of quadriceps femoris muscle length on neural activation during isometric and concentric contractions. Journal of applied physiology. 2003;94(3):983-990.

19. Brockett CL, Morgan DL, Proske U. Human hamstring muscles adapt to eccentric exercise by changing optimum length. Medicine and science in sports and exercise. $2001 ; 33(5): 783-790$. 
"Reliability of Isometric and Eccentric Isokinetic Shoulder External Rotation" by Papotto BM et al. Journal of Sport Rehabilitation

(C) 2015 Human Kinetics, Inc.

Figure 1. Frontal View of Testing Set-Up

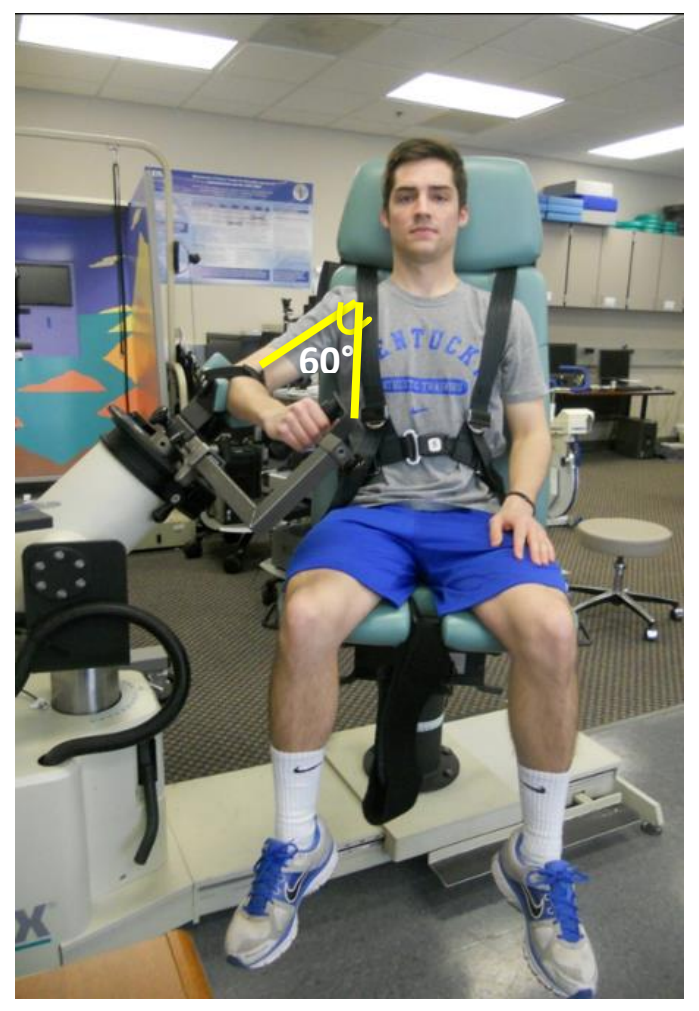

Figure 2. Transverse View of Testing Set-Up

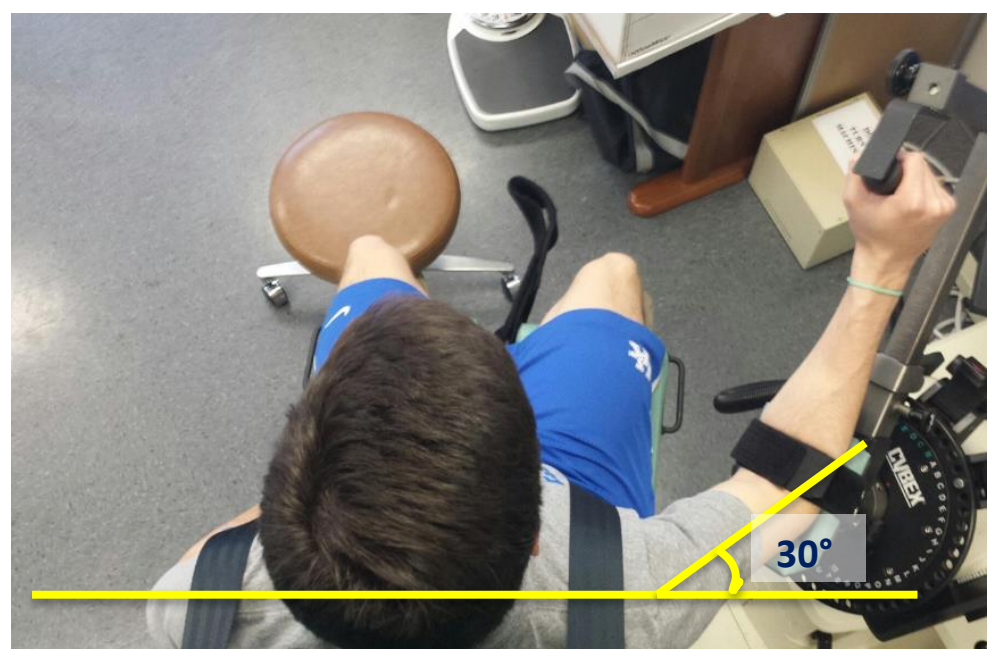


"Reliability of Isometric and Eccentric Isokinetic Shoulder External Rotation" by Papotto BM et al. Journal of Sport Rehabilitation

(C) 2015 Human Kinetics, Inc.

Figure 3. Force-Length Relationship of a Single Subject

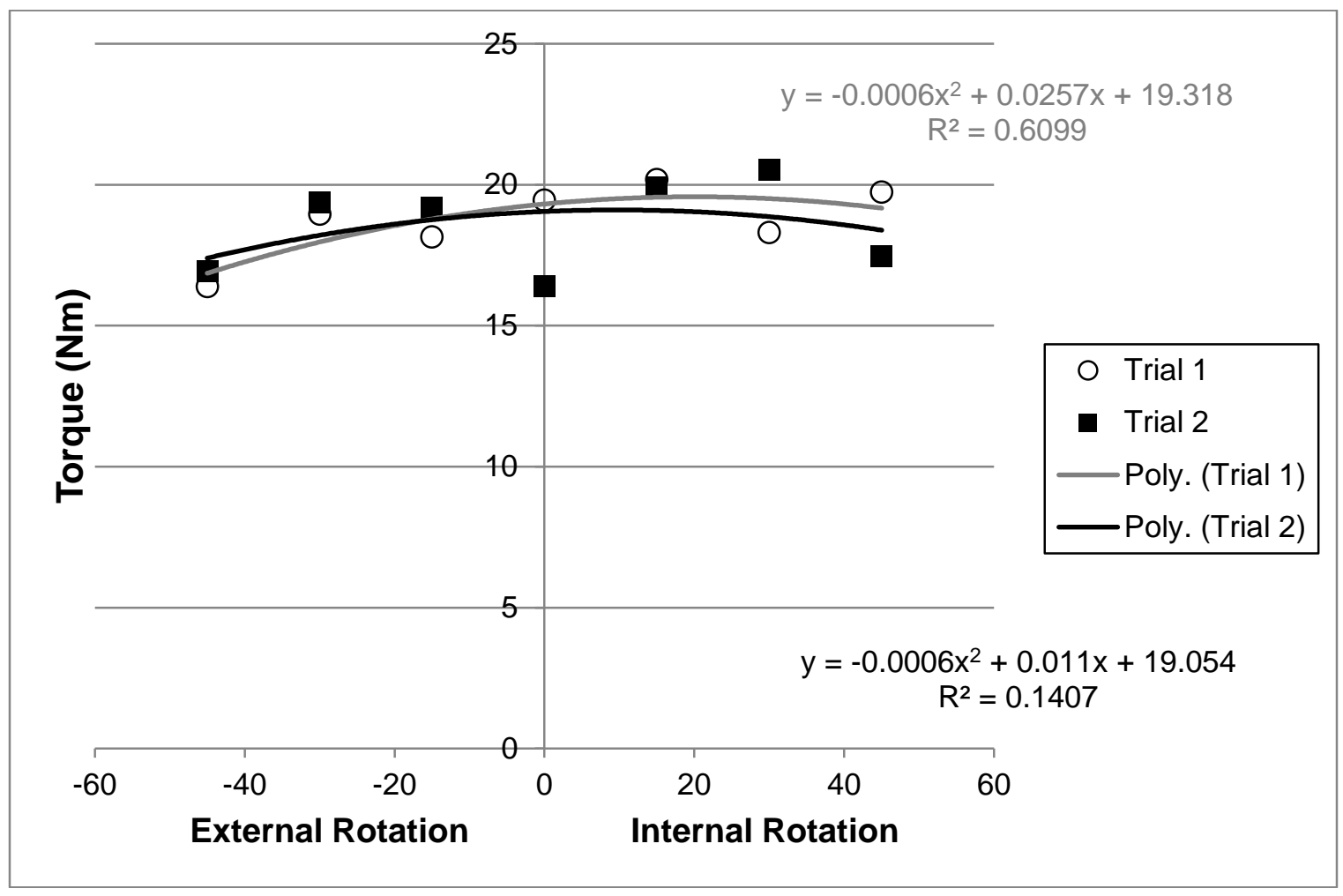

Graphic representation of isometric strength testing the 7 angles tested ranging from $45^{\circ} \mathrm{ER}$ $45^{\circ} \mathrm{IR}$. $2^{\text {nd }}$ order polynomial trend line was plotted to represent the torque generated across the arc of motion. Arm position, in degrees of internal and external rotation, is plotted on the horizontal axis while torque, in Newton-meters, is on the vertical axis. 
"Reliability of Isometric and Eccentric Isokinetic Shoulder External Rotation" by Papotto BM et al. Journal of Sport Rehabilitation

(C) 2015 Human Kinetics, Inc.

Table 1. Isometric and Eccentric Mean Values

\begin{tabular}{|c|c|c|c|c|c|c|}
\hline Measure & $\begin{array}{c}\text { Day } \\
1\end{array}$ & SD & Day 2 & SD & Day 3 & SD \\
\hline \multicolumn{7}{|c|}{ ISOMETRIC MEASURES } \\
\hline $\mathrm{ER} 45^{\circ}(\mathrm{Nm})$ & 15.4 & 6.2 & 14.7 & 5.8 & 15.7 & 7.4 \\
\hline $\mathrm{ER} 30^{\circ}(\mathrm{Nm})$ & 16.5 & 6.5 & 16.4 & 5.9 & 16.7 & 7.8 \\
\hline $\mathrm{ER} 15^{\circ}(\mathrm{Nm})$ & 18.1 & 6.5 & 16.9 & 6.2 & 18.3 & 9.7 \\
\hline $0^{\circ}(\mathrm{Nm})$ & 17.9 & 6.7 & 17.8 & 6.9 & 18.5 & 8.1 \\
\hline $\operatorname{IR~} 15^{\circ}(\mathrm{Nm})$ & 20.4 & 8.9 & 17.8 & 7.3 & 19.7 & 8.8 \\
\hline IR $30^{\circ}(\mathrm{Nm})$ & 20.4 & 8.7 & 20.1 & 8.9 & 20.4 & 9.7 \\
\hline $\mathrm{IR} 45^{\circ}(\mathrm{Nm})$ & 20.7 & 10.5 & 20.4 & 9.4 & 21.3 & 10.2 \\
\hline $\begin{array}{l}\text { Est. Angle of } \\
\text { Pk Torque } \\
\left({ }^{\circ}\right)\end{array}$ & 14.7 & 73.8 & 37.2 & 166.6 & 20.8 & 83.4 \\
\hline \multicolumn{7}{|c|}{ ECCENTRIC MEASURES } \\
\hline $\begin{array}{l}\text { Peak Torque } \\
(\mathrm{Nm})\end{array}$ & 22.9 & 8.0 & 22.8 & 7.4 & 23.8 & 8.6 \\
\hline $\begin{array}{l}\text { Avg Angular } \\
\text { Impulse } \\
\left(\mathrm{Nm}^{*} \mathrm{~s}\right)\end{array}$ & 32.1 & 11.9 & 31.8 & 11.0 & 34.1 & 12.9 \\
\hline $\begin{array}{l}\text { Avg Angle of } \\
\text { Pk Torque }\left(^{\circ}\right)\end{array}$ & -11.1 & 26.5 & -5.0 & 24.0 & -12.0 & 18.4 \\
\hline
\end{tabular}

Abbreviations: SD, standard deviation; ER, external rotation; Nm, newton-meter; Est. Angle of Pk Torque, estimated angle of peak torque; Avg Angular Impulse, average angular impulse during eccentric contractions; $\mathrm{Nm}^{*}$ s, newton-meter*second; Avg Angle of $\mathrm{Pk}$ Torque, average angle of peak torque 
"Reliability of Isometric and Eccentric Isokinetic Shoulder External Rotation" by Papotto BM et al. Journal of Sport Rehabilitation

(C) 2015 Human Kinetics, Inc.

Table 2. Between Day Reliability Values of Isometric and Eccentric Shoulder External Rotation

\begin{tabular}{|c|c|c|c|c|}
\hline Measure & Day & ICC & SEM & MDC \\
\hline \multicolumn{5}{|c|}{ ISOMETRIC MEASURES } \\
\hline \multirow{2}{*}{ ER $45^{\circ}(\mathrm{Nm})$} & $1-2$ & 0.92 & 1.7 & 2.4 \\
\hline & $2-3$ & 0.90 & 2.1 & 3.0 \\
\hline \multirow{2}{*}{$\mathrm{ER} 30^{\circ}(\mathrm{Nm})$} & $1-2$ & 0.85 & 2.4 & 3.4 \\
\hline & $2-3$ & 0.91 & 2.0 & 2.8 \\
\hline \multirow{2}{*}{$\mathrm{ER} 15^{\circ}(\mathrm{Nm})$} & $1-2$ & 0.96 & 1.3 & 1.8 \\
\hline & $2-3$ & 0.90 & 2.5 & 3.5 \\
\hline \multirow{2}{*}{$0^{\circ}(\mathrm{Nm})$} & $1-2$ & 0.97 & 1.2 & 1.7 \\
\hline & $2-3$ & 0.93 & 2.0 & 2.9 \\
\hline \multirow{2}{*}{ IR $15^{\circ}(\mathrm{Nm})$} & $1-2$ & 0.93 & 2.1 & 3.0 \\
\hline & $2-3$ & 0.95 & 1.8 & 2.6 \\
\hline \multirow{2}{*}{ IR $30^{\circ}(\mathrm{Nm})$} & $1-2$ & 0.99 & 0.9 & 1.3 \\
\hline & $2-3$ & 0.99 & 1.1 & 1.6 \\
\hline \multirow{2}{*}{ IR $45^{\circ}(\mathrm{Nm})$} & $1-2$ & 0.97 & 1.7 & 2.5 \\
\hline & $2-3$ & 0.97 & 1.7 & 2.4 \\
\hline Est. Angle Pk & $1-2$ & -0.003 & 120.4 & 170.2 \\
\hline Torque $\left({ }^{\circ}\right)$ & $2-3$ & 0.65 & 73.9 & 104.6 \\
\hline \multicolumn{5}{|c|}{ ECCENTRIC MEASURES } \\
\hline \multirow{2}{*}{$\begin{array}{l}\text { Peak Torque } \\
(\mathrm{Nm})\end{array}$} & $1-2$ & 0.97 & 1.3 & 1.8 \\
\hline & $2-3$ & 0.98 & 1.2 & 1.7 \\
\hline Avg Anglar & $1-2$ & 0.97 & 2.0 & 2.8 \\
\hline Impulse (Nms) & $2-3$ & 0.98 & 1.9 & 2.7 \\
\hline Avg Angle Pk & $1-2$ & 0.93 & 6.5 & 9.2 \\
\hline Torque $\left(^{\circ}\right)$ & $2-3$ & 0.51 & 14.8 & 20.9 \\
\hline
\end{tabular}

Abbreviations: ICC, intraclass correlation coefficient; SEM, standard error of measurement; MDC, minimal detectable change; ER, external rotation; IR, internal rotation; Nm, newton-meter; Est. Angle Pk Torque, estimated angle of peak torque; Avg Angular Impulse, average angular impulse; $\mathrm{Nm}^{*} \mathrm{~s}$, measure of angular impulse: newtonmeter*second; Avg Angle Pk Torque, average angle of peak torque 